\title{
The non-dosage compensated Lsp I $\alpha$ gene of Drosophila melanogaster escapes acetylation by MOF in larval fat body nuclei, but is flanked by two dosage compensated genes Vikki M Weake and Maxwell J Scott*
}

Address: Centre for Functional Genomics, Institute of Molecular BioSciences, Massey University, Private Bag 11 222, Palmerston North, New Zealand

Email: Vikki M Weake -VMW@stowers-institute.org; Maxwell J Scott* - M.J.Scott@massey.ac.nz

* Corresponding author

Published: 19 May 2007

BMC Molecular Biology 2007, 8:35 doi:10.1186/147/-2199-8-35
Received: 24 October 2006

Accepted: 19 May 2007

This article is available from: http://www.biomedcentral.com/I47/-2/99/8/35

(c) 2007 Weake and Scott; licensee BioMed Central Ltd.

This is an Open Access article distributed under the terms of the Creative Commons Attribution License (http://creativecommons.org/licenses/by/2.0), which permits unrestricted use, distribution, and reproduction in any medium, provided the original work is properly cited.

\begin{abstract}
Background: In Drosophila melanogaster dosage compensation of most X-linked genes is mediated by the male-specific lethal (MSL) complex, which includes MOF. MOF acetylates histone $\mathrm{H} 4$ at lysine 16 (H4KI 6ac). The X-linked Larval serum protein one $\alpha(L s p / \alpha)$ gene has long been known to be not dosage compensated. Here we have examined possible explanations for why the Lsp/ $\alpha$ gene is not dosage compensated.
\end{abstract}

Results: Quantitative RNase protection analysis showed that the genes flanking $L s p / \alpha$ are expressed equally in males and females and confirmed that $L s p / \alpha$ is not dosage compensated. Unlike control X-linked genes, Lsp I $\alpha$ was not enriched for H4KI6ac in the third instar larval fat body, the tissue in which the gene is actively expressed. X-linked $L s p / \alpha$ promoter-lacZ reporter transgenes are enriched for H4KI6ac in third instar larval fat body. An X-linked reporter gene bracketed by $L s p / \alpha$ flanking regions was dosage compensated. One of the genes flanking $L s p / \alpha$ is expressed in the same tissue. This gene shows a modest enrichment for H4KI6ac but only at the part of the gene most distant from Lsp / $\alpha$. Phylogenetic analyses of the sequences of the genomes of 12 Drosophila species shows that $L s p / \alpha$ is only present within the melanogaster subgroup of species.

Conclusion: $L s p / \alpha$ is not modified by the MSL complex but is in a region of the $X$ chromosome that is regulated by the MSL complex. The high activity or tissue-specificity of the $L s p / \alpha$ promoter does not prevent regulation by the MSL complex. The regions flanking $L s p / \alpha$ do not appear to block access by the MSL complex. Lsp / $\alpha$ appears to have recently evolved within the melanogaster subgroup of Drosophila species. The most likely explanation for why $L s p / \alpha$ is not dosage compensated is that the gene has not evolved a mechanism to independently recruit the MSL complex, possibly because of its recent evolutionary origin, and because there appears to be a low level of bound MSL complex in a nearby gene that is active in the same tissue. 


\section{Background}

$\mathrm{X}$ chromosome dosage compensation in Drosophila melanogaster is achieved by doubling the transcription of most genes on the single X chromosome in male flies [1-4]. This dosage compensation is mediated by the male-specific lethal (MSL) complex containing both protein and noncoding RNA components [4]. The genes encoding the MSL proteins were identified through mutagenesis screens, in which the mutant phenotype is male lethality ( male $\underline{s} p e-$ cific lethal mutations) $[5,6]$. Five proteins form the core of the MSL complex: MSL1, MSL2, MSL3, MLE and the histone acetyl transferase MOF, which acetylates histone $\mathrm{H} 4$ at lysine 16 (H4K16ac) [7,8]. The acetylase activity of MOF is essential for male viability [6]. There is considerable evidence that these proteins associate in a complex that localises specifically to the male X chromosome [912]. The male specificity of the complex is due to MSL2, which is negatively regulated at the translational level by the female-specific protein SXL $[13,14]$.

MSL1 and MSL2 are essential and sufficient for binding of a partial complex to $\sim 35$ high affinity sites along the $\mathrm{X}$ chromosome $[9,12,15,16]$. Two of these sites correspond to the genes encoding the non-coding RNAs, roX1 and roX2 ( $\underline{R N A}$ on the $\underline{X}$ chromosome), which are part of the MSL complex [17]. These RNAs are redundant, but essential for dosage compensation, although approximately $5 \%$ of male roX 1 roX2 double mutants survive as adults [18]. It has been proposed that the high affinity binding regions constitute chromatin entry sites, at which the MSL complex assembles prior to spreading into flanking regions of chromatin [17]. However, chromatin entry sites are not essential for targeting of the MSL complex [19,20]. An alternative model proposes that the MSL complex is targeted to individual X-linked genes by uncharacterised sequence motifs that are absent from autosomal genes [20]. This model is supported by recent high-resolution chromatin immunoprecipitation studies (ChIP-chip), which found that MSL binding is gene specific [21-23]. However, autosomal genes inserted on the $\mathrm{X}$ chromosome can be dosage compensated [24], indicating that bound MSL complex may be able to regulate the expression of nearby genes in the chromatin domain.

The X-linked gene Larval serum protein 1 alpha (Lsp1 $\alpha)$ appears to escape dosage compensation by the MSL complex $[25,26]$. LSP $1 \alpha$ is an abundant protein expressed in the fat body of third instar larvae [27], which forms a complex with autosomal LSP1 proteins to act as nutrient reservoir for pupal development [28]. LSP1 $\alpha$ is not essential for survival, as flies carrying mutations in all of the Lsp1 genes are viable [29]. Lsp1 $\alpha$ could escape regulation by the MSL complex by one of two distinct possibilities. Either, it is flanked by boundary elements that block access of the MSL complex or it lacks characteristics required to attract the MSL complex, such as DNA sequences or chromatin composition. Both of these models are supported by the observation that the $L s p 1 \alpha$ gene is either partially or fully dosage compensated when relocated to two other locations on the male $\mathrm{X}$ chromosome [30].

In this study we examine possible explanations for why $L s p 1 \alpha$ is not dosage compensated.

\section{Results \\ Lsp I $\alpha$ is flanked by dosage compensated genes}

In order to determine whether $L s p 1 \alpha$ is the only gene within its chromosomal region to escape dosage compensation, the dosage compensation status of the genes flanking $L s p 1 \alpha$ was examined. Previous work indicated that the

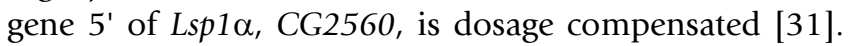
Several other genes in the region near $L s p 1 \alpha$ were identified after publication of the Drosophila genome sequence.

Five putative genes exist in the region immediately surrounding $L s p 1 \alpha$ as predicted by cDNA evidence from the Drosophila genome project [32]: CG15926, CG2560 (referred to as L12 by [31]), CG15730, CG2556 and CG11146 (Figure 1A). Since CG11146 is separated from $L s p 1 \alpha$ by two intervening genes, it was not examined in this study. The developmental stage in which $L s p 1 \alpha$, CG15926, CG2560 and CG2556 are expressed was determined by Northern RNA hybridisation analysis (Figure 1B and $1 C$ ). As expected $L s p 1 \alpha$ is very highly expressed and easily detected in total RNA from third instar larvae (Figure 1B). CG2560 is expressed in all larval stages, as previously reported. Four transcripts were detected for CG2556, which is downstream of $L s p 1 \alpha$ (Figure 1C). These transcripts are expressed differentially throughout development but importantly are present in third instar larvae. Thus, genes 5' and 3' of $L s p 1 \alpha$ are expressed at the same stage of development. Transcripts from CG15730, the gene immediately 3 ' of $L s p 1 \alpha$, were not detected at any of the developmental stages analysed using $2 \mu \mathrm{g}$ of poly(A)+ mRNA, or in adults using RT-PCR (data not shown). It is possible that this intron-less gene may be expressed in only a few cells, or may require stimuli not present under standard conditions. Since expression could not be detected, it was not examined further in this study. CG15926 transcripts are present in 2-fold higher levels in hemisected (head plus thorax) adult males compared to females as shown by RNase protection (data not shown), thus the dosage compensation status of this gene could not be determined. There were slightly higher transcript levels of the rp49 loading control in whole adult females than males (Figure 1C) as shown previously [33], possibly due to strong ovarian expression. For this reason, hemisected adults or sexed larvae were used in this study for determining a gene's dosage compensation status. 
A
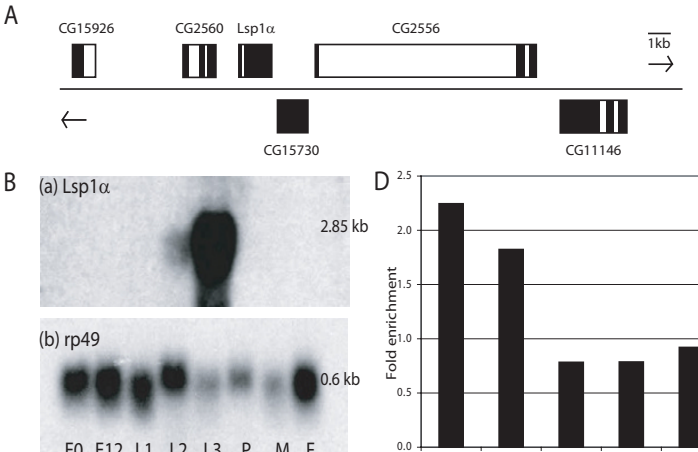

E0 E12 L1 L2 L3 $P$ P $\quad M$ F
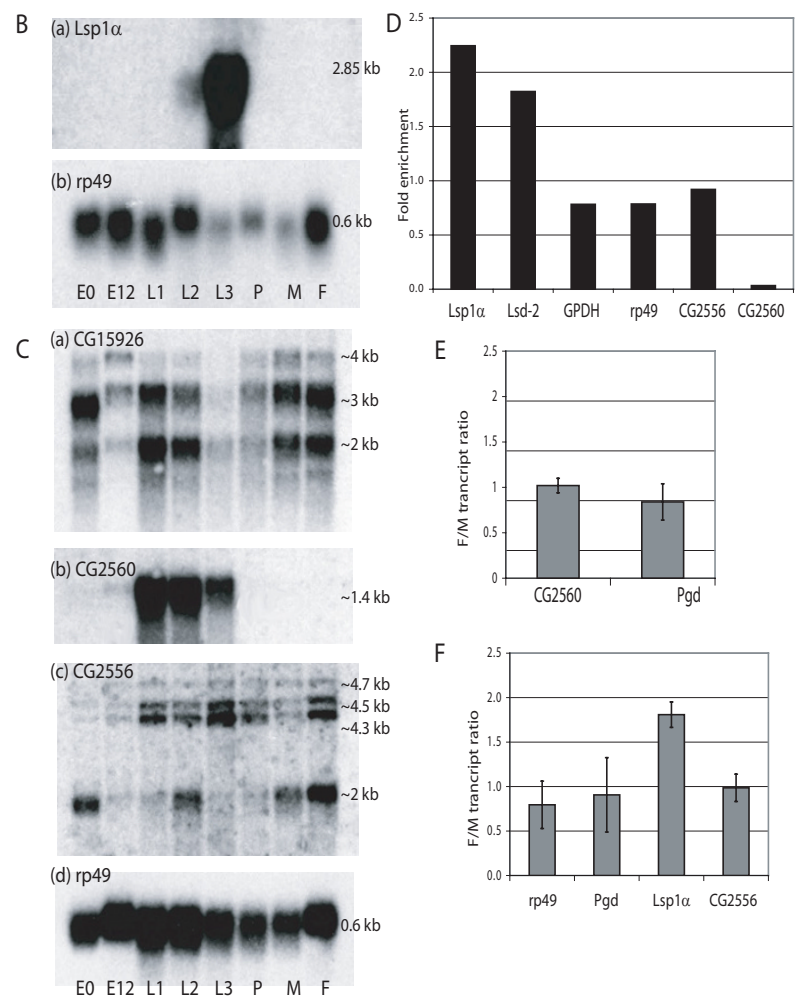

$\mathrm{E}$

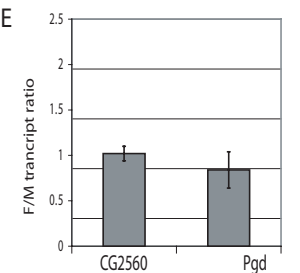

$\mathrm{F}$

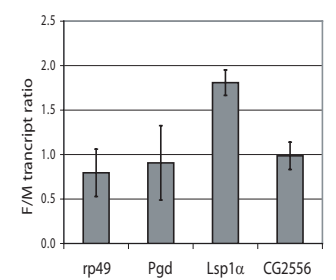

Figure I

The genes flanking $L s p / \alpha$ are dosage compensated, and CG2556 is expressed in the same tissue as $L s p / \alpha$ (A) The predicted genes flanking $L s p / \alpha$ (exons in black). (B) Northern RNA hybridization analysis of $10 \mu \mathrm{g}$ of total RNA from embryos $0-2 \mathrm{~h}$ after laying (E0), embryos $12 \mathrm{~h}$ after laying (EI2), first instar larvae (LI), second instar larvae (L2), third instar larvae (L3), pupae (P), adult males (M), and adult females $(F)$. All embryo, larval and pupae samples consist of mixed male and female RNA. Northerns were probed with cDNAs for $L s p / \alpha$ (a) and rp49 (b). (C) Northern hybridization analysis of $2 \mu \mathrm{g}$ of poly $(\mathrm{A})$ mRNA from the developmental stages described in (B). Northerns were probed with cDNAs for CGI5926 (a), CG2560 (b), CG2556 (c) and rp49 (d). (D) Real-time RT-PCR of Lsp / $\alpha$, Lsd-2, Gpdh, rp49, CG2556 and CG2560 in male fat body and whole third instar male larvae cDNA. The fold enrichment of each transcript in fat body compared to whole larvae cDNA is shown.

(E)CG2560 and Pgd mRNA was measured by RNase protection relative to rp49 in male and female first instar larvae.

Mean female/male transcript ratios and $95 \%$ confidence intervals are indicated for 3 experiments. (F) Lsp / $\alpha$, CG2556, Pgd and rp49 mRNA was measured by RNase protection in male and female $y w$ staged-third instar larvae. Mean female/male transcript ratios and $95 \%$ confidence intervals are indicated for 3 experiments.
Multi-probe quantitative RNase protection analysis was used to determine the dosage compensation status of CG2560 and CG2556 genes in first and third instar larvae respectively. Control probes detected transcripts from the $\mathrm{X}$-linked dosage compensated 6-phosphogluconate dehydrogenase (Pgd) [34,35] and constitutive autosomal ribosomal protein 49 (rp49) [33] genes. First instar larvae were sexed using a stock in which only the male larvae express GFP. Female to male CG2560 and Pgd transcript ratios were normalised to $r p 49$, as the 3 probes were analysed simultaneously. A female to male transcript ratio of one indicates that a gene is compensated, whereas a female to male ratio of two suggests that a gene is not compensated. CG2560 and $P g d$ have female to male transcript ratios of $1.02 \pm 0.08$ and $0.84 \pm 0.20$ respectively (Figure 1E) indicating that these genes are both dosage compensated. This concurs with the CG2560 transcript ratios obtained in second instar larvae using an alternative method [31]. Single probe RNase protection of CG2556 and Lsp1 $\alpha$ was conducted in male and female $y w$ staged-third instar larvae relative to $P g d$ and $r p 49$, as both transcripts are present at this developmental stage (Figure 1B,C). Female to male CG2556, $L s p 1 \alpha$ and $P g d$ transcript ratios were not normalised to $r p 49$, as the 4 probes were analysed separately due to the similar size of the protected RNAs. Rp49 and Pgd have female to male transcript ratios of $0.79 \pm 0.27$ and $0.91 \pm 0.42$ respectively (Figure $1 \mathrm{~F}$ ), demonstrating equivalent RNA levels are present in both sexes. CG2556 and $L s p 1 \alpha$ have female to male transcript ratios of $0.99 \pm 0.15$ and $1.81 \pm 0.14$ respectively (Figure $1 \mathrm{~F}$ ), indicating that CG2556 is dosage compensated but $L s p 1 \alpha$ is not. These results show that two of the genes flanking $L s p 1 \alpha$ are dosage compensated, and suggest that $L s p 1 \alpha$ is unique within its chromosomal domain in escaping regulation by the MSL complex.

The regions flanking Lsp I $\alpha$ do not contain elements able to block dosage compensation of an X-linked transgene

The genes flanking $L s p 1 \alpha$ are dosage compensated, but $L s p 1 \alpha$ is not. One possible explanation for why $L s p 1 \alpha$ escapes dosage compensation is that flanking sequence elements somehow block access of the MSL complex to the gene. To test this possibility, the genomic regions between $L s p 1 \alpha$ and CG2560 (I) and between $L s p 1 \alpha$ and CG2556 (I2) were inserted either side of an arm-lacZ reporter construct (I-arm-lacZ-I2). We have previously shown that X-linked arm-lacZ transgenes are fully dosage compensated [36,37], although it is not known if this is due to local spreading of the MSL complex or to direct recruitment of the complex. If the $L s p 1 \alpha$ flanking regions contain elements able to block access of the MSL complex, it follows that X-linked I-arm-lacZ-I2 transgenic lines will not be dosage compensated, and will exhibit female to male reporter activity ratios of two. Due to the presence of promoter sequences within the (I) region, female to male 
reporter activity ratios were analysed in adult flies, in which only the armadillo promoter is active, rather than in third instar larvae in which both the armadillo and $L s p 1 \alpha$ promoter sequences are active. All autosomal and Xlinked arm-lacZ lines had female to male $\beta$-galactosidase activity ratios of $\sim 1$ (Table 1 ). Both autosomal I-arm-lacZI2 lines also had female to male $\beta$-galactosidase activity ratios of $\sim 1$. The X-linked I-arm-lacZ-I2 line exhibited a female to male $\beta$-galactosidase activity ratio of $\sim 1$, indicating that the (I) and (I2) regions do not contain elements able to prevent the MSL complex from binding to and dosage compensating arm-lacZ on the X chromosome.

The precise chromosomal location of these X-linked transgenes was determined by inverse PCR. The I-arm-lacZI2:19C3 transgene has inserted between the X-linked CG1631 and CG15462 genes that are uncharacterised with respect to expression and are part of an approx. $140 \mathrm{~kb}$ gene poor region of the chromosome (19C2 to 19C5). The nearest genes that showed significant binding of MSL1 and MSL3 in embryos are Rab10 (19C1) and l(1)G0004 (19C6) that are approximately $95 \mathrm{~kb}$ upstream and $45 \mathrm{~kb}$ downstream respectively from the site of insertion of the I-arm-lacZ-I2 transgene [21,23] (Additional file 1; Panel B). The arm-lacZ:10D8 transgene has inserted in the first intron of the X-linked inaF (CG2457) gene, which encodes a protein with calcium channel regulator activity involved in rhodopsin mediated signalling that is expressed in the head and eye of adult flies [38]. Although, it has not been reported if inaF is dosage compensated, significant binding of MSL1 is detected at the 3' end of this gene in embryos [23].

\section{Lsp I $\alpha$ is not enriched for histone $\mathrm{H} 4$ acetylated at lysine I 6 in male larval fat body nuclei}

There was no binding of MSL1 or MSL3 to Lsp1 $\alpha$ in embryos or of MSL3 to Lsp1 $\alpha$ in SL2 cells [21-23] (Additional file 1; Panel D). This would be the expected result since $L s p 1 \alpha$ is not dosage compensated. In SL2 cells, 90\% of MSL3 binding clusters were within expressed genes, with an enrichment in the middle and 3 ' end [21]. Since $L s p 1 \alpha$ is not actively expressed in SL2 cells it was possible that MSL complex could be binding to $L s p 1 \alpha$ in the tissue in which the gene is expressed, namely third instar larval fat body. As acetylation of $\mathrm{H} 4$ at lysine 16 is dependent on the MOF component of the MSL complex, we measured the relative level of $H 4 \mathrm{~K} 16 \mathrm{ac}$ on $L s p 1 \alpha$ in larval fat body nuclei by chromatin immunoprecipitation analysis. Chromatin from hand-dissected male $y w$ larval fat body was immunoprecipitated with antibody against H4K16ac. The X-linked, fat body-expressed Lipid storage droplet-2 (Lsd-2) and $P g d$ genes showed 3 - 10 fold enrichments after immunoprecipitation compared to the autosomal gene, Glycerol-3-phosphate dehydrogenase (Gpdh), which had a relative enrichment of one (Figure 2). The differential levels of enrichment within Pgd have been observed previously [39]. Lsp1 $\alpha$ exhibited no enrichment for H4K16ac, confirming the prediction that actively expressed $L s p 1 \alpha$ would not be acetylated by MOF as it is not dosage compensated.

\section{Lsp I $\alpha$ promoter-lacZ $X$-linked transgenes are enriched for H4KI 6ac in larval fat body}

Since the majority of MSL target genes are widely expressed [21-23], we next investigated if the Lsp1 $\alpha$ gene was not enriched for H4K16ac because of the high activity and tissue specificity of its promoter. The $L s p 1 \alpha$ gene promoter was fused to the lacZ reporter gene and two Xlinked lines containing this gene construct were obtained. Chromatin from male Lsp1 $\alpha(-573$ to +20$)$-lacZ:9B4 and Lsp1 $\alpha(-573$ to +20$)-$ lacZ: $19 E 7$ third instar larval fat bodies was immunoprecipitated with antibody against H4K16ac (Figure 2). As for the $y w$ strain, the X-linked Lsd-2 and Pgd genes were enriched for H4K16ac. The two X-linked $L s p 1 \alpha$ $(-573$ to +20$)$-lacZ transgenes also showed 3-fold enrichments within lac $Z$. Thus the lack of enrichment of H4K16ac within $L s p 1 \alpha$ is not because of the tissue-specificity of the gene promoter.

There are two possible explanations for why X-linked $L s p 1 \alpha$-lacZ transgenes were enriched for H4K16ac in larval

Table I: Mean male and female $\beta$-galactosidase activities and ratios in X-linked and autosomal l-arm-lacz-I2 and arm-lacZ adults.

\begin{tabular}{|c|c|c|c|c|c|c|c|}
\hline \multirow[t]{2}{*}{ Construct } & \multirow[t]{2}{*}{ location } & \multicolumn{2}{|c|}{ Dose } & \multirow[t]{2}{*}{$\mathrm{n}^{\mathrm{a}}$} & \multirow[t]{2}{*}{ Mean female/male ratio of activityb } & \multirow[t]{2}{*}{ Mean male activity/copy } & \multirow[t]{2}{*}{ Mean female activity/copy } \\
\hline & & M & $\mathrm{F}$ & & & & \\
\hline arm-lacZ & 68D3 (A) & I & 1 & 3 & $0.99 \pm 0.09 c$ & $2.36 \pm 0.13$ & $2.33 \pm 0.09$ \\
\hline arm-lacZ & 79A4 (A) & 2 & 2 & 3 & $0.92 \pm 0.09$ & $2.61 \pm 0.16$ & $2.39 \pm 0.12$ \\
\hline arm-lacZ & I0D8 (X) & 1 & 2 & 3 & $1.12 \pm 0.26$ & $4.27 \pm 0.51$ & $2.36 \pm 0.27$ \\
\hline I-arm-lacZ-12 & $21 \mathrm{~A} 2(\mathrm{~A})$ & 2 & 2 & 3 & $1.00 \pm 0.05$ & $2.46 \pm 0.43$ & $2.45 \pm 0.35$ \\
\hline I-arm-lacZ-I2 & $57 A 6(A)$ & 2 & 2 & 3 & $0.99 \pm 0.07$ & $2.62 \pm 0.20$ & $2.58 \pm 0.13$ \\
\hline I-arm-lacZ-12 & $19 \mathrm{C3}(\mathrm{X})$ & 1 & 2 & 3 & $1.11 \pm 0.06$ & $4.02 \pm 0.27$ & $2.22 \pm 0.12$ \\
\hline
\end{tabular}

a Number of independent experiments

b $100 \mathrm{mOD} \mathrm{min}^{-1} \mathrm{mg}$ protein

c $95 \%$ confidence intervals are indicated. 


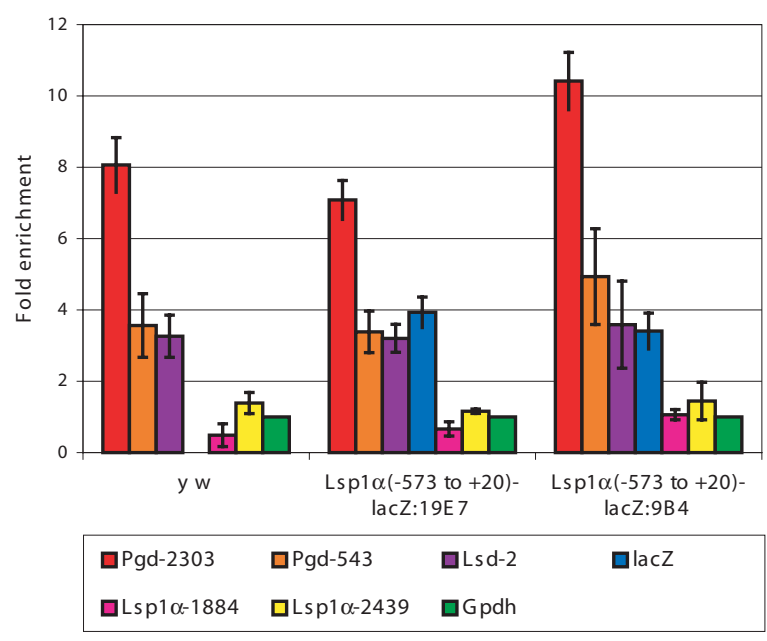

Figure 2

Lsp I $\alpha$ is not acetylated at $H 4 K I$ 6, but X-linked $L s p I \alpha$ (-573 to +20)-lacZ transgenes are. Chromatin from y w, Lsp I $\alpha(-573$ to +20$)$-lacZ: I 9E7 and Lsp I $\alpha(-573$ to +20)lacZ:9B4 male third instar larval fat body nuclei immunoprecipitated with antibody against H4KI6ac. The fold enrichment of immunoprecipitated DNA relative to input DNA is shown for two experiments (95\% confidence intervals indicated). Fold enrichment is normalized to Gpdh, which is set to I. A 3 - 10 fold enrichment is observed for the control genes Pgd and Lsd-2 and both X-linked Lsp I $\alpha(-573$ to +20$)$ lac $Z$ transgenes. However, no enrichment is observed for $L s p / \alpha$. Two primer sets were used to amplify different regions within the Pgd and $L s p / \alpha$ genes. All primers are designed to the 3' UTR or 3' region of the open reading frame with the exception of the Pgd-543 set, which is within the second intron but towards the 5 ' end of the Pgd gene.

fat body. Either the transgenes have inserted near MSL complex target genes or alternatively MSL complex is directly recruited to the lacZ gene. The latter would seem less likely as the gene is of bacterial origin and MSL complex is not recruited to autosomally integrated lac $Z$ transgenes [37]. The Lsp1 $\alpha(-573$ to +20$)$-lacZ:9B4 transgene has inserted in the first intron of the CG15309 gene. While there are no MSL1 or MSL3 binding sites within CG15309, there are clusters of sites within the closely adjacent l(1)G0230 gene in embryos, SL2 and Clone 8 cells (Additional file 1; Panel C). The Lsp1 $\alpha(-573$ to +20)-lacZ:19E7 transgene has inserted between the CG1529 and Ntf-2 (CG1740) genes. There are clusters of MSL1 and MSL3 binding sites within both the CG1529 and Ntf-2 genes in embryos, SL2 and Clone 8 cells [21,23] (Additional file 1; Panel A). While it is not known if CG15309, CG1529 or
$N t f-2$ gene are actively expressed and targeted by the MSL complex in third instar larval fat body, Ntf-2 is likely to be expressed in this tissue based on mutant phenotypes [40]. That MSL complex distribution appears to remain largely stable across development [21,22] would suggest that MSL complex would be bound to the CG15309, CG1529 and $N t f-2$ genes in larval fat body.

\section{CG2556 is expressed in larval fat body but shows only a moderate enrichment for H4KI 6ac at the 3' end}

If $\mathrm{X}$-linked $L s p 1 \alpha$-lacZ transgenes are enriched for H4K16ac because they have inserted near MSL target genes then why is $L s p 1 \alpha$ not enriched for H4K16ac as the flanking genes are dosage compensated? Since there is a strong correlation between MSL complex binding and gene transcription [21], one possibility is that the flanking genes are not transcribed in third instar larval fat body. Both CG2560 and CG2556 are expressed in third instar larvae (Figure 1C), but their tissue distribution is unknown. In order to determine whether CG2560 and CG2556 are expressed in the fat body, real-time RT-PCR of cDNA from male fat body and whole larvae was conducted on CG2560 and CG2556 relative to the fat body specific genes $L s p 1 \alpha$ [27] and Lsd-2 [41], and the constitutively expressed genes Gpdh and $r p 49$. Lsp $1 \alpha$ and $L s d-2$ show 2.24 and 1.82-fold enrichments respectively in fat body cDNA compared to whole third instar larval cDNA, while Gpdh and rp49 show 0.78 and 0.79-fold enrichments respectively (Figure 1D). CG2560 demonstrates 0.03 -fold enrichment in fat body cDNA compared to whole third instar larval cDNA, indicating that it is not expressed in fat body tissue. This is consistent with its proposed function as a structural component of the larval cuticle [42] and specific expression in dorsal and ventral epidermis in late embryos [43]. CG2556 shows 0.92-fold enrichment in fat body cDNA compared to whole third instar larval cDNA, indicating that it is expressed in both this tissue and other parts of the larvae. Transcripts for the gene immediately $3^{\prime}$ of $L s p 1 \alpha, C G 15730$, were not detected in third instar larvae hence it is unlikely that the MSL complex is targeted to this gene in fat body tissue.

Since CG2556 is also expressed in fat body we performed ChIP experiments with isolated fat body nuclei and antiH4K16ac antibody. There was no enrichment with a 5' UTR fragment (fold enrichment of $1.10 \pm 0.09$ relative to Gpdh in $y w$ male fat bodies). Further, the 3' UTR of CG2556 is only moderately enriched for this histone modification (fold enrichment of $1.93 \pm 0.77$ relative to Gpdh in $y w$ male fat bodies), suggesting MSL complex is not present in high levels in this region of the chromosome in third instar larval fat body, although the gene is clearly dosage compensated. The moderate enrichment of H4K16ac at the 3' end of CG2556 is consistent with the high-density ChIP-chip profiles that found that the MSL 
complex binds to intragenic regions, particularly the $3^{\prime}$ end of X-linked genes $[21,23]$.

\section{Lsp I $\alpha$ has most likely evolved recently within the melanogaster subgroup of Drosophila species}

It had been suggested that $L s p 1 \alpha$ has arisen from a duplication and translocation of an autosomal Lsp1 $\beta$ gene [44]. The sequencing of the genomes of twelve Drosophila species [45] allowed us to address when $L s p 1 \alpha$ evolved. As expected homologues of $L s p 1 \beta$ and $L s p 1 \gamma$ were found in all Drosophila species examined. Lsp1 $\alpha$ homologues, however, are only present in the melanogaster subgroup of species, which are thought to have descended from a common ancestor 8 - 12 million years ago [46] (Figure $3)$. In these species $L s p 1 \alpha$ lies between homologues of CG2560 and CG15730, while in the remainder of the species these genes are immediately adjacent (including $D$. ananassae, which is part of the melanogaster group but not sub-group). Thus it would appear that $L s p 1 \alpha$ arose relatively recently within the melanogaster subgroup of species and so may not have yet evolved MSL binding sites. However, a tree based on maximum likelihood analysis of LSP1 sequences (Methods) suggests that $L s p 1 \alpha$ arose before the divergence of Drosophila species (Figure 3). If so, then $L s p 1 \alpha$ has been precisely lost on at least four separate occasions (ancestor of: D. ananassae, obscura group, willistoni group and Drosophila subgenus). More likely some residues within LSP1 $\alpha$ proteins may not be under the same functional constraints as in LSP $1 \beta$ proteins leading to the observed divergence. The $L s p 1 \beta$ gene seems to be particularly prone to duplication events as duplicated Lsp1 $\beta$ genes were found in D. ananassae, D. grimshawi and D. willistoni genome sequences (Figure 3). The two Lsp1 $\beta$ genes are immediately adjacent to each other in these three species. The maximum likelihood analysis suggests the duplication events have occurred recently within each of the three species.

\section{Discussion}

$L s p 1 \alpha$ is a well characterised example of a non-dosage compensated gene [25]. In contrast, two genes situated less than $5 \mathrm{~kb}$ either side of it, are expressed equivalently in male and female larvae. That $L s p 1 \alpha$ escapes regulation by the MSL complex was shown by the lack of enrichment for H4K16ac in the tissue in which it is expressed. These results are consistent with high-resolution ChIP-chip studies that found that MSL complex binding was genespecific [21-23]. Further, the complex bound predominantly to constitutively expressed genes. $L s p 1 \alpha$ is certainly not a housekeeping gene, but rather is a gene that is very highly expressed in a specific cell type and a specific stage of development. Since $L s p 1 \alpha$ is not an essential gene [29] there would have been little evolutionary pressure to acquire MSL binding sites since it evolved, which appears to have been relatively recently in the melanogaster sub-

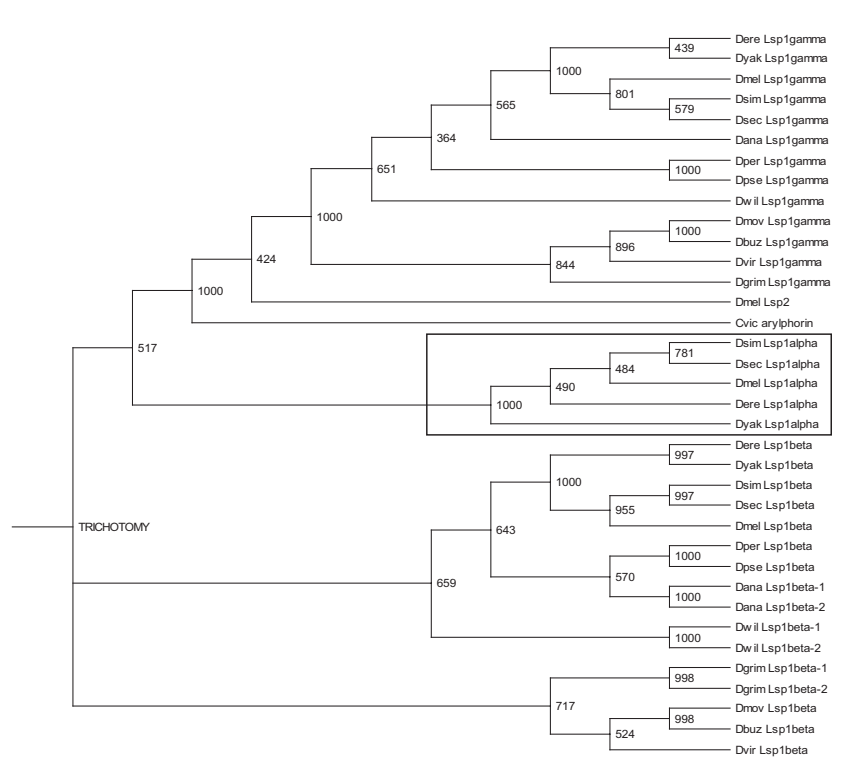

Figure 3

Lsp I $\alpha$ is present in five closely related Drosophila species, but is absent in more distantly related species.

Maximum likelihood tree based on the ungapped regions of a ClustalX alignment (additional file 4) of the LSPI $\alpha$, LSPI $\beta$ and LSPI $\gamma$ protein sequences from $D$. melanogaster (Dmel), $D$. yakuba (Dyak), D. erecta (Dere), D. simulans (Dsim), D. sechellia (Dsec), D. mojavensis (Dmoj), D. buzzatii (Dbuz), D. ananassae (Dana), D. pseudoobscura (Dpse), D. willistoni (Dwil), D. grimshawi (Dgri), D. persimilis (Dper) and D. virilis (Dvir). The Lsp I-like protein arylphorin from the blowfly Calliphora vicina [6I] is also included and bootstrap support is shown on the branches. LSPI $\alpha$ homologues (in the boxed region) are present only in $D$. melanogaster, $D$. yakuba, D. erecta, $D$. simulans and $D$. sechellia.

group of species. The only gene in the $L s p 1 \alpha$ gene region that is bound to MSL1 and MSL3 in embryos is Rab40 [21,23] (Additional file 1), which is approx. $30 \mathrm{~kb}$ upstream of $L s p 1 \alpha$. Thus $L s p 1 \alpha$ appears to have arisen within a region of the $\mathrm{X}$ chromosome that has few strong MSL binding sites in whole embryos.

In the two-step model for MSL complex targeting to $\mathrm{X}$ chromosome genes, the complex is initially bound to sequences of higher affinity and then spreads locally to nearby expressed genes [17]. Such a mechanism would explain why autosomal genes inserted onto the X chromosome can be dosage compensated [24]. According to this model, it would be anticipated that the MSL complex could spread locally from flanking dosage compensated genes that are active in third instar larval fat cells to $L s p 1 \alpha$. Of the two flanking dosage compensated genes, only the downstream CG2556 gene is transcribed in third instar larval fat cells. However, we could not detect any enrichment for H4K16ac at the 5' end and only a modest enrich- 
ment for H4K16ac at the 3' end, which is $\sim 11 \mathrm{~kb}$ from $L s p 1 \alpha$. Thus it appears that MSL complex does not spread to the $L s p 1 \alpha$ gene in its normal chromatin location because the level of complex bound to nearby active genes in fat body nuclei is low. The ChIP-chip studies identified several examples of neighbouring genes that have differential MSL binding profiles. It remains to be determined if, like $L s p 1 \alpha$, the unbound genes are not enriched for $\mathrm{H} 4 \mathrm{~K} 16 \mathrm{ac}$ in the cells in which they are actively transcribed. If so, it would be of interest to know if these genes, like $L s p 1 \alpha$ [30], can respond to the MSL complex when relocated to other locations on the X chromosome.

We found no evidence for boundary elements flanking the Lsp1 $\alpha$ gene that could prevent access of the MSL complex to an active gene. An arm-lac $Z$ reporter gene bracketed by sequences that flank the $L s p 1 \alpha$ gene was fully dosage compensated when inserted onto the X chromosome. The MSL complex could reach the I-arm-lacZ-I2 transgene by spreading from a nearby gene with bound complex or could bind directly to the transgene. The I-arm-lacZ-I2 transgene inserted into a very gene poor region that is largely devoid of bound MSL complex in embryos and SL2 cells $[21,23]$. The nearest gene with significant levels of bound complex in embryos is approx. $45 \mathrm{~kb}$ from the transgene insertion site. The MSL complex can spread hundreds of kilobases from an autosomally integrated roX gene [17], so it is possible that the MSL complex could spread $45 \mathrm{~kb}$ along the male $\mathrm{X}$ chromosome. It is also possible that MSL complex may be bound to more genes in this region in adults, the stage we measured $\beta$-galactosidase activity. However, while MSL complex binding pattern is not invariant, it is largely similar in distinct cell types [21,22]. Thus, while it is clear that $L s p 1 \alpha$ is not flanked by sequences that prevent access of the MSL complex, we cannot conclude if this is because they fail to block local spreading of the complex. If MSL complex does not spread locally to the integrated arm-lacZ reporter gene, then the transgene must independently recruit MSL complex. This may simply be because the MSL complex preferentially binds to expressed genes [21]. However, transcription is not sufficient to recruit complex. Legube et al (2006) [22] found that the promoter regions of some MSL1 target genes are enriched in DREF binding sites. The arm promoter has several possible DREF binding sites (not shown). armadillo is an X-linked constitutively expressed gene [47]. The $1.6 \mathrm{~kb}$ arm fragment in the armlacZ construct contains 5' flanking sequence, the two major start sites of transcription, the first intron and start of second exon [47]. There is significant binding of MSL1 and MSL3 to this fragment of the arm gene in embryos and SL2 cells respectively [21,23]. Thus the arm promoter may contribute to recruitment of MSL complex to an actively expressed arm-lacZ transgene. While arm-lacZ transgenes are fully dosage compensated at several loca- tions on the X chromosome [36,37], there is no binding of the MSL complex to autosomally integrated arm-lacZ transgenes, which are equally expressed in males and females [37]. Thus if the arm-lacZ transgene can independently recruit MSL complex, it can only do so in an X chromosomal environment. Clearly additional studies are needed to identify what features of the arm-lacZ transgene are important for recruitment of the MSL complex. The development of site-specific integration systems for Drosophila $[48,49]$ should greatly facilitate such studies as various gene constructs could all be tested at the same locations on the $\mathrm{X}$ chromosome.

\section{Conclusion}

In this study we have examined possible explanations for why the X-lined $L s p 1 \alpha$ gene is not dosage compensated. $L s p 1 \alpha$ is not enriched for H4K16ac in third instar larval fat body, the tissue in which the gene is actively expressed. Thus $L s p 1 \alpha$ is not compensated because the chromatin is not modified by the MSL complex at the gene's normal location on the $\mathrm{X}$ chromosome. $L s p 1 \alpha$ is in a region of the $\mathrm{X}$ chromosome that is subject to regulation by the MSL complex, as genes flanking and within $5 \mathrm{~kb}$ of $L s p 1 \alpha$ are dosage compensated. Lsp1 $\alpha$ does not appear to be surrounded by sequence elements that prevent access of the MSL complex as these flanking regions did not prevent a reporter gene from being dosage compensated when inserted on the $\mathrm{X}$ chromosome. The stage-specificity or high activity of the $L s p 1 \alpha$ promoter does not prevent dosage compensation because X-linked lacZ transgenes under the control of the $L s p 1 \alpha$ promoter were enriched for $\mathrm{H} 4 \mathrm{~K} 16 \mathrm{ac}$ in larval fat body. Only one of the genes flanking $L s p 1 \alpha$ is expressed in the same tissue as $L s p 1 \alpha$ and this gene showed no enrichment for H4K16ac at its 5' end (end closest to $L s p 1 \alpha$ ) and showed only a modest enrichment at its 3 ' end in larval fat body. Homologues of $L s p 1 \alpha$ were found only in the melanogaster subgroup of species. The most likely explanation for why $L s p 1 \alpha$ is not dosage compensated is that the gene has not evolved a mechanism to independently recruit the MSL complex, possibly because of its recent evolutionary origin, and because there appears to be a low level of bound MSL complex in a nearby gene that is active in the same tissue.

Recent ChIP-chip analyses have identified several expressed X-linked genes that are not bound by the MSL complex. The significance of this study is that we have addressed possible mechanisms by which one such gene escapes regulation by the MSL complex.

\section{Methods}

\section{Northern RNA Hybridisation Analysis}

RNA was extracted using TRIzol reagent (Invitrogen) and RNA secure (Ambion). Poly(A) RNA was isolated using 
oligo(dT) cellulose (Roche) and Northern hybridization analysis conducted as described in [50].

\section{Real-time RT-PCR Assays}

RNA from 10 male third instar larvae or 10 male third instar larval fat bodies was treated with Turbo DNase (Ambion) and reverse transcribed (Roche). Quantitative real-time PCR was conducted in triplicate (variation $<15 \%)$ using the LightCycler FastStart DNA Master ${ }^{\text {PLus }}$ SYBR Green I reaction mix (Roche) in a LightCycler Instrument (Roche) on $2 \mu \mathrm{l}$ of 10 -fold or 100 -fold diluted cDNA in a $10 \mu \mathrm{l}$ reaction volume. Information about the primers used in this study is available upon request. An annealing temperature of $55^{\circ} \mathrm{C}$ and an extension of $12 \mathrm{~s}$ were used. The crossing point (CP) was automatically determined by the LightCycler software (Roche). Fold enrichment was determined by $2^{\wedge}$ (CP whole larvae - CP fat body). The primer sets used were; $L s p 1 \alpha$ (5'CTCGCTGACGGACAAC and 5'GGGCTCAGTAAGGTCCA), Rp49 (5'CGGTTACGGATCGAACA and 5'CGATCTCGCCGCAGTAAA), Lsd-2 (5'AGTGTACTAGCCGATACG and 5'TCTGACTCCCGGATCT), CG2560 (5'ATGGCAATGCTTACGGT and 5'GAGGTGGCTGATAATCGTAG), CG2556 (5'TGGTAATGGCGGCCTAAA and 5'TGCGAGTGTTCAGCTTG), Gpdh (5'GTGCCCGACCTGGTTGAG and 5'CTTGCCTTCAGGTGACGC).

\section{Quantitative RNase Protection Assays}

Quantitative RNase protection was conducted on 3-4 separate collections of matched female and male FM7I, $P\{w[+m C]=A c t G F P\} J M R 3 / c(1) D X, y^{1} f^{1}$ first instar larvae or $y w$ blue food-staged third instar larvae [51] using the RPA III kit (Ambion). Antisense RNA probes for CG2560, $P g d, r p 49, L s p 1 \alpha$ and CG2556 were synthesized with T7, T3 or SP6 RNA polymerase (Roche). The relative radioactivity of the probes was adjusted by increasing the concentration of $\left[\alpha-{ }^{32} P\right] C T P$ and decreasing the concentration of unlabeled CTP in the reaction cocktails. Unincorporated radionucleotide was removed with the NucAway spin column (Ambion). The CG2556 probe was gel purified (Qiagen). 3 - 10 fold molar excess of probe was added to $4 \mu \mathrm{g}$ (CG2560, Pgd, rp49 and Lsp1 $\alpha$ ) or $20 \mu \mathrm{g}$ (CG2556) of DNase-treated phenol/chloroform purified RNA and annealed overnight with RNA in the presence of pellet paint co-precipitant (Novagen); protected RNA probes were detected and quantified on 5\% polyacrylamide urea gels with the Storm 860 phosphorimager (Molecular Dynamics) or the FLA-5000 phosphorimager (Fujifilm). The quantification value of each protected RNA species was corrected for the background value of the sample of yeast RNA hybridized to probe treated with RNase. The mass of RNA used in each assay was determined to be within the linear range of the RNase protection assay for each protected RNA. The sizes of the protected RNAs were
$366 \mathrm{nt}$ for CG2560, $391 \mathrm{nt}+294 \mathrm{nt}$ for $L s p 1 \alpha, 268 \mathrm{nt}$ for CG2556, $171 \mathrm{nt}+43 \mathrm{nt}$ for Pgd and $312 \mathrm{nt}$ for $r p 49$.

\section{Generation of Transgenic Fly Lines}

All recombinant DNA manipulations were carried out using standard procedures [50] unless otherwise specified. The 883 bp region between $L s p 1 \alpha$ and CG2560 including the $L s p 1 \alpha$ promoter (I) and 4596 bp region between the 3' end of $L s p 1 \alpha$ and the 5 ' end of CG2556 (I2) were amplified by PCR from genomic $y$ w D. melanogaster DNA, and cloned into pGEM-T Easy (Promega). The primer sequences used are available upon request. PstINotI and EcoRI-StuI linkers were inserted into the PstI site $3^{\prime}$ of lacZ-SV4O and the EcoRI site 5' of armadillo in pCaSpeR-arm-ßgal (arm-lacZ) [47]. The blunt-ended NotI (I) and NotI (I2) fragments were cloned into the StuI and NotI sites of this plasmid respectively, generating I-armlacZ-I2. The 593 bp $L s p 1 \alpha$ promoter $(-573$ to +20$)$ was amplified by PCR from genomic $y \mathrm{w} D$. melanogaster DNA, and cloned into pGEM-T Easy (Promega). The bluntended NotI promoter fragment was cloned into the StuI site of pCaSpeR-arm- $\beta$ gal in which the EcoRI/Asp718 armadillo promoter fragment had been replaced with a linker containing EcoRI,BamHI, NheI, StuI and Asp718 sites, generating the $L s p 1 \alpha(-573$ to +20$)$-lacZ construct. Transgenic flies carrying these constructs were generated from $y w$ stock using standard procedures [52]. The site of transgene integration was determined where possible using inverse PCR, and all transgenic lines consist of single insertions as determined by Southern hybridisation analysis.

\section{$\beta$-galactosidase Assays}

$\beta$-galactosidase assays were performed on hemisected adults as described in [36]. Assays were performed in triplicate on 3 separate collections unless otherwise stated. Means and standard deviations of activities and ratios were calculated from the 3 separate collections.

\section{Chromatin Immunoprecipitation Assays}

Chromatin immunoprecipitation was based on the procedures described in [53-55] with additional modifications suggested by Edwin Smith (Emory University, 2005, personal communications). Fat bodies manually dissected from 200 male third instar larvae were quick frozen then ground in liquid nitrogen, and homogenized in $5 \mathrm{ml}$ of $10 \mathrm{mM}$ Hepes [pH 7.6], $1 \mathrm{mM}$ EDTA, $150 \mathrm{mM} \mathrm{NaCl}, 0.6 \%$ Triton X-100, $4 \mathrm{mM}$ DTT, $10 \mathrm{mM}$ sodium butyrate with protease inhibitors (Roche). After centrifugation at $500 \times$ $g$ for $30 \mathrm{~s}$ at $4^{\circ} \mathrm{C}$, the supernatant was stored on ice for 5 $\mathrm{min}$, followed by centrifugation at $1500 \times \mathrm{g}$ for $10 \mathrm{~min}$ at $4^{\circ} \mathrm{C}$. Pelleted nuclei were resuspended in $360 \mu \mathrm{l}$ of nucleus isolation buffer (NIB: $0.25 \mathrm{M}$ sucrose, $10 \mathrm{mM}$ Tris- $\mathrm{HCl}[\mathrm{pH}$ 7.4], $3 \mathrm{mM} \mathrm{CaCl}, 10 \mathrm{mM}$ sodium butyrate, protease inhibitors) and incubated with formaldehyde at 
a final concentration of $1 \%$ for $10 \mathrm{~min}$ at room temperature with shaking. Nuclei were pelleted at $1500 \times g$ for 10 min at $4{ }^{\circ} \mathrm{C}$, resuspended in $360 \mu \mathrm{l}$ of NIB, and pelleted. Nuclei were resuspended in $200 \mu \mathrm{l}$ of $1 \%$ SDS, $50 \mathrm{mM}$ Tris-HCl [pH 8.1], 10 mM EDTA, 10 mM sodium butyrate with protease inhibitors for $10 \mathrm{~min}$ on ice, followed by sonication in the presence of 425-600 mm acid-washed glass beads (Sigma) for $6 \times 30 \mathrm{~s}$ pulses at power level 1.5 (VirSonic). This sonication produced DNA fragments with a mean size of $500 \mathrm{bp}$. The sonicated chromatin lysate was diluted with $1.8 \mathrm{ml}$ of chromatin immunoprecipitation buffer (CIB: $25 \mathrm{mM}$ Tris-HCl [pH 8.0], $137 \mathrm{mM}$ $\mathrm{NaCl}, 2.7 \mathrm{mM} \mathrm{KCl}, 1 \%$ Triton X-100, 1 mM EDTA, $10 \mathrm{mM}$ sodium butyrate) and centrifuged at $14,000 \times \mathrm{g}$ for $10 \mathrm{~min}$ at $4{ }^{\circ} \mathrm{C}$. Input DNA was purified from $200 \mu \mathrm{l}$ of this supernatant by incubation with $10 \mu \mathrm{l} 10 \mathrm{mg} / \mathrm{ml}$ RNase for 10 $\min$ at $37^{\circ} \mathrm{C}$, and $20 \mu \mathrm{l} 10 \mathrm{mg} / \mathrm{ml}$ proteinase $\mathrm{K}$ for $6 \mathrm{~h}$ at $37^{\circ} \mathrm{C}$. Crosslinks were reversed by incubation for $6 \mathrm{~h}$ at $65^{\circ} \mathrm{C}$. DNA was purified using the QIAquick PCR purification kit (Qiagen).

The remaining $1.8 \mathrm{ml}$ of sonicated chromatin lysate was pre-incubated with $60 \mu \mathrm{l} 50 \%$ Protein A Sepharose Bead suspension (Sigma), protease inhibitors and $9 \mu \mathrm{l} 10 \mathrm{mg} /$ $\mathrm{ml}$ salmon sperm DNA (ssDNA) for $1 \mathrm{~h}$ with shaking at $4{ }^{\circ} \mathrm{C} .6 \mu \mathrm{l}$ of rabbit anti histone $\mathrm{H} 4$ (Ac16) antibody (AHP417; Serotec) was pre-bound to $120 \mu \mathrm{l} 50 \%$ Protein A Sepharose Beads suspension in $1 \mathrm{ml}$ of CIB with protease inhibitors, $10 \mu \mathrm{l} 10 \mathrm{mg} / \mathrm{ml} \mathrm{ssDNA}$ and $20 \mu \mathrm{l} 10 \mathrm{mg} /$ ml BSA (NEB) for $1 \mathrm{~h}$ with shaking at $4{ }^{\circ} \mathrm{C}$. The pre-cleared chromatin lysate was incubated with the pre-bound antibody-beads for $3 \mathrm{~h}$ at $4^{\circ} \mathrm{C}$ with shaking. Following this the beads were washed successively in: $150 \mathrm{mM} \mathrm{NaCl}, 20$ $\mathrm{mM}$ Tris-HCl [pH 8.0], $2 \mathrm{mM}$ EDTA, $1 \%$ Triton X-100, $0.1 \%$ SDS, $10 \mathrm{mM}$ sodium butyrate; $500 \mathrm{mM} \mathrm{NaCl}, 20$ mM Tris-HCl [pH 8.0], 2 mM EDTA, 1\% Triton X-100, $0.1 \%$ SDS, $10 \mathrm{mM}$ sodium butyrate; $250 \mathrm{mM} \mathrm{LiCl}, 10 \mathrm{mM}$ Tris-HCl [pH 8.0], 1 mM EDTA, 1\% sodium deoxycholate, 1\% IGEPAL CA-630 (Sigma), $10 \mathrm{mM}$ sodium butyrate; TE buffer. Beads were rinsed and suspended in TE Buffer. Immunoprecipitated DNA (ChIP DNA) was incubated with $1 \mu \mathrm{l} 10 \mathrm{mg} / \mathrm{ml} \mathrm{RNase}$ for $10 \mathrm{~min}$ at $37^{\circ} \mathrm{C}$, followed by incubation with $5 \mu \mathrm{l} 10 \%$ SDS and $2 \mu \mathrm{l} 10 \mathrm{mg} / \mathrm{ml}$ proteinase $\mathrm{K}$ for $6 \mathrm{~h}$ at $37^{\circ} \mathrm{C}$. Crosslink reversal and DNA purification were conducted as described for input DNA.

Quantitative real-time PCR was conducted as described for real-time RT-PCR assays. Undiluted immunoprecipitated DNA $(2 \mu \mathrm{l})$ and 100-fold diluted input DNA $(2 \mu \mathrm{l})$ were assayed with each primer set in triplicate (variation $<15 \%)$. The primer pairs used were; Lsp1 $\alpha-1184$ (5'CTCGCTGACGGACAAC and 5'GGGCTCAGTAAGGTCCA), Lsp1 $\alpha$-2439 (5'CTTCAAGTTGTAGATCTGATAACATTCCGA and 5'GCTTAACAGAGAAATCTGAATACGTTGG), Pgd-543 (5'GGATAAGCAGGTGGAAGTAGGAAG and 5'ACACTT-
GTGGTTACGGTTTTCG)， Pgd-2303 (5'GAAGGGCACGGGCAAGTG and 5'CAATGCCGCCGTAATTAAGTCTC), Lsd-2 (5'GAAACACACGCACACGG and 5'TCCCAGCGAGCGTACAA), Gpdh (5'GTGCCCGACCTGGTTGAG and 5'CTTGCCTTCAGGTGACGC), lacZ (5'GCGCGAATTGAATTATGGCCC and 5'GCCATGTGCCTTCTTCCG). The Pgd and Gpdh primer sets are identical to those used in a previous study [39]. The identity of the PCR products amplified by each primer combination was confirmed by sequencing. Fold enrichment was determined by $2^{\circ} \mathrm{CP}$ input X-linked gene - CP ChIP X-linked gene) $/ 2{ }^{\circ} \mathrm{CP}$ Gpdh - CP ChIP Gpdh).

\section{Computational Identification and Analysis of LSPI Proteins from Drosophila species}

The Drosophila melanogaster LSP1 $\alpha$ (GenBank accession no. NP 511138), LSP1及 (GenBank accession no.

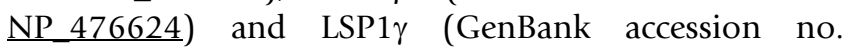
NP 523868) protein sequences were used to search the nucleotide sequences available in "DroSpeGe: Drosophila Species Genomes" [45] using tBlastn. The scaffolds on which the LSP1 homologues were identified are described in additional files 2 and 3. LSP1 $\beta$ and LSP $1 \gamma$ had independently been identified in D. buzzatii and D. pseudoobscura [44], as had LSP1 $\gamma$ from D. simulans (GenBank accession no. AAB71667). An alignment of the dataset was performed in ClustalX [56], ambiguous bases and gaps were removed from the alignment using PAUP*4.10b [57]. Using ProtTest [58], the optimal model of sequence evolution was determined to be WaG [59]. A maximum likelihood analysis was performed on the data in Phyml using the WaG model with 100 bootstrap replicates [60]. The D. simulans LSP1 $\alpha$ sequence is incomplete due to a gap in the genomic sequence.

\section{Authors' contributions}

VW carried out all of the experiments and drafted the manuscript. MS conceived of the study, and participated in its design and coordination and helped to draft the manuscript. All authors read and approved the final manuscript.

\section{Additional material}

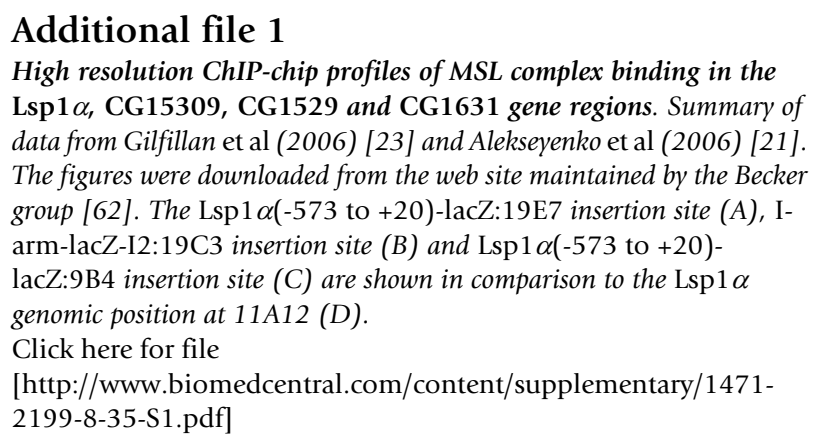




\section{Additional file 2}

Lsp1 $\alpha$ is flanked by CG2560 and CG15730 in five Drosophila species, but these genes lie immediately adjacent to one another in the other species that lack Lsp1 $\alpha$

Click here for file

[http://www.biomedcentral.com/content/supplementary/1471-

2199-8-35-S2.doc]

\section{Additional file 3}

Lsp1 gene identification in Drosophila species.

Click here for file

[http://www.biomedcentral.com/content/supplementary/1471-

2199-8-35-S3.doc]

\section{Additional file 4}

Clustal X alignment of Drosophila Lsp1 sequences and Lsp1-like protein arylphorin from $\mathrm{C}$. vicina.

Click here for file

[http://www.biomedcentral.com/content/supplementary/14712199-8-35-S4.pdf]

\section{Acknowledgements}

We thank Edwin Smith for advice on chromatin immunoprecipitation assays, Tobius Straub for help accessing ChIP-chip profiles, Peter Lockhart and Richard Carter for advice and assistance on generation of the Lsp I tree and Malcolm Cook for assistance with the binding site analysis.

This work was supported by a grant from the RSNZ Marsden Fund (MJS) and a FRST high achiever doctoral scholarship to VMW.

\section{References}

I. Lucchesi JC, Kelly WG, Panning B: Chromatin remodeling in dosage compensation. Annu Rev Genet 2005, 39:615-65I.

2. Straub T, Dahlsveen IK, Becker PB: Dosage compensation in flies: mechanism, models, mystery. FEBS Lett 2005, 579(I5):3258-3263.

3. Taipale M, Akhtar A: Chromatin mechanisms in Drosophila dosage compensation. Prog Mol Subcell Biol 2005, 38: $123-149$.

4. Straub T, Becker PB: Dosage compensation: the beginning and end of generalization. Nat Rev Genet 2007, 8(1):47-57.

5. Belote JM, Lucchesi JC: Male-specific lethal mutations of Drosophila melanogaster. Genetics 1980, 96(I):165-186.

6. Hilfiker A, Hilfiker-Kleiner D, Pannuti A, Lucchesi JC: mof, a putative acetyl transferase gene related to the Tip60 and MOZ human genes and to the SAS genes of yeast, is required for dosage compensation in Drosophila. EMBO J 1997, l 6(8):2054-2060.

7. Akhtar A, Becker PB: Activation of transcription through histone $\mathrm{H} 4$ acetylation by MOF, an acetyltransferase essential for dosage compensation in Drosophila. Mol Cell 2000, 5(2):367-375.

8. Smith ER, Pannuti A, Gu W, Steurnagel A, Cook RG, Allis CD, Lucchesi JC: The Drosophila MSL complex acetylates histone H4 at lysine 16, a chromatin modification linked to dosage compensation. Mol Cell Biol 2000, 20(I):3।2-3I8.

9. Gorman M, Franke A, Baker BS: Molecular characterization of the male-specific lethal-3 gene and investigations of the regulation of dosage compensation in Drosophila. Development 1995, I 2 I(2):463-475.

10. Copps K, Richman R, Lyman LM, Chang KA, Rampersad-Ammons J, Kuroda MI: Complex formation by the Drosophila MSL proteins: role of the MSL2 RING finger in protein complex assembly. EMBO J 1998, I7( I 8):5409-54I7.

II. Scott MJ, Pan LL, Cleland SB, Knox AL, Heinrich J: MSLI plays a central role in assembly of the MSL complex, essential for dosage compensation in Drosophila . EMBO J 2000 , 19(I): I44-155.

12. Gu W, Szauter P, Lucchesi JC: Targeting of MOF, a putative histone acetyl transferase, to the $X$ chromosome of Drosophila melanogaster. Dev Genet 1998, 22(I):56-64.

13. Bashaw G], Baker BS: The msl-2 dosage compensation gene of Drosophila encodes a putative DNA-binding protein whose expression is sex specifically regulated by Sex-lethal. Development 1995, I 2 I (10):3245-3258.

14. Bashaw G], Baker BS: The regulation of the Drosophila msl-2 gene reveals a function for Sex-lethal in translational control. Cell 1997, 89(5):789-798.

15. Palmer MJ, Richman R, Richter L, Kuroda MI: Sex-specific regulation of the male-specific lethal-I dosage compensation gene in Drosophila. Genes Dev 1994, 8(6):698-706.

16. Lyman LM, Copps K, Rastelli L, Kelley RL, Kuroda MI: Drosophila male-specific lethal-2 protein: structure/function analysis and dependence on MSL-I for chromosome association. Genetics 1997, I47(4): 1743-1753.

17. Kelley RL, Meller VH, Gordadze PR, Roman G, Davis RL, Kuroda MI: Epigenetic spreading of the Drosophila dosage compensation complex from roX RNA genes into flanking chromatin. Cell 1999, 98(4):5। 3-522.

18. Meller VH, Rattner BP: The roX genes encode redundant malespecific lethal transcripts required for targeting of the MSL complex. EMBO J 2002, 21 (5): 1084-1091.

19. Oh H, Bone JR, Kuroda Ml: Multiple classes of MSL binding sites target dosage compensation to the $\mathbf{X}$ chromosome of Drosophila . Curr Biol 2004, I4(6):48I-487.

20. Fagegaltier D, Baker BS: $\mathbf{X}$ chromosome sites autonomously recruit the dosage compensation complex in Drosophila males. PLoS Biol 2004, 2(II):e34I.

21. Alekseyenko AA, Larschan E, Lai WR, Park PJ, Kuroda MI: High-resolution ChIP-chip analysis reveals that the Drosophila MSL complex selectively identifies active genes on the male $\mathbf{X}$ chromosome. Genes Dev 2006, 20(7):848-857.

22. Legube G, McWeeney SK, Lercher MJ, Akhtar A: X-chromosomewide profiling of MSL-I distribution and dosage compensation in Drosophila. Genes Dev 2006, 20(7):87I-883.

23. Gilfillan GD, Straub T, de Wit E, Greil F, Lamm R, van Steensel B, Becker PB: Chromosome-wide gene-specific targeting of the Drosophila dosage compensation complex. Genes Dev 2006, 20(7):858-870.

24. Lucchesi JC, Manning JE: Gene dosage compensation in Drosophila melanogaster. Adv Genet 1987, 24:371-429.

25. Roberts DB, Evans-Roberts S: The $\mathbf{X}$-linked alpha-chain gene of Drosophila LSP-I does not show dosage compensation. Nature 1979, 280(5724):69I-692.

26. Brock HW, Roberts DB: The LSPI-alpha gene is not dosage compensated in the Drosophila melanogaster species subgroup. Biochem Genet 1982, 20(3-4):287-296.

27. Lepesant JA, Levine M, Garen A, Lepesant-Kejzlarvoa J, Rat L, Somme-Martin G: Developmentally regulated gene expression in Drosophila larval fat bodies. J Mol Appl Genet 1982, I(5):37I-383.

28. Roberts DB, Wolfe J, Akam ME: The developmental profiles of two major haemolymph proteins from Drosophila melanogaster. J Insect Physiol 1977, 23(7):87I-878.

29. Roberts DB, Jowett T, Hughes J, Smith DF, Glover DM: The major serum protein of Drosophila larvae, larval serum protein I, is dispensable. Eur J Biochem I991, I 95(I): |95-201.

30. Ghosh S, Chatterjee RN, Bunick D, Manning JE, Lucchesi JC: The LSPI-alpha gene of Drosophila melanogaster exhibits dosage compensation when it is relocated to a different site on the X chromosome. EMBO J 1989, 8(4): II9I-II 96.

31. Ghosh S, Lucchesi JC, Manning JE: The non-dosage compensated LSPI-alpha gene of Drosophila melanogaster lies immediately downstream of the dosage compensated LI2 gene. Mol Gen Genet 1992, 233(I-2):49-52.

32. Rubin GM, Hong L, Brokstein P, Evans-Holm M, Frise E, Stapleton M, Harvey DA: A Drosophila complementary DNA resource. Science 2000, 287(546I):2222-2224.

33. O'Connell $P$, Rosbash M: Sequence, structure and codon preference of the Drosophila ribosomal protein 49 gene. Nucleic Acids Research 1984, I 2(13):5495-5513. 
34. Gutierrez AG, Christensen AC, Manning JE, Lucchesi JC: Cloning and dosage compensation of the 6-phosphogluconate dehydrogenase gene (Pgd+) of Drosophila melanogaster. Dev Genet 1989, 16:155-|6|.

35. Bowman JT, Simmons JR: Gene modulation in Drosophila : dosage compensation of Pgd+ and Zw+ genes. Biochem Genet 1973 , I0(4):3|9-33|.

36. Fitzsimons HL, Henry RA, Scott MJ: Development of an insulated reporter system to search for cis-acting DNA sequences required for dosage compensation in Drosophila. Genetica 1999, 105:215-226.

37. Henry RA, Tews B, Li X, Scott MJ: Recruitment of the male-specific lethal (MSL) dosage compensation complex to an autosomally integrated ro $\mathbf{X}$ chromatin entry site correlates with an increased expression of an adjacent reporter gene in male Drosophila. Journal of Biological Chemistry 200I, 276(34):31953-31958.

38. Li C, Geng C, Leung HT, Hong YS, Strong LL, Schneuwly S, Pak WL: INAF, a protein required for transient receptor potential $\mathrm{Ca}(2+)$ channel function. Proc Natl Acad Sci U S A 1999, 96(23): I3474-13479.

39. Smith ER, Allis CD, Lucchesi JC: Linking global histone acetylation to the transcription enhancement of $X$-chromosomal genes in Drosophila males. Journal of Biological Chemistry 200I, 276(34):3|483-3|486.

40. Bhattacharya A, Steward R: The Drosophila homolog of NTF-2, the nuclear transport factor-2, is essential for immune response. EMBO Rep 2002, 3(4):378-383.

4I. Teixeira L, Rabouille C, Rorth P, Ephrussi A, Vanzo NF: Drosophila Perilipin/ADRP homologue Lsd2 regulates lipid metabolism. Mechanisms of Development 2003, I 20: I07|-108I.

42. Drysdale RA, Crosby MA: FlyBase: genes and gene models. Nucleic Acids Res 2005:D390-395.

43. Tomancak P, Beaton A, Weiszmann R, Kwan E, Shu S, Lewis SE, Richards S, Ashburner M, Hartenstein V, Celniker SE, Rubin GM: Systematic determination of patterns of gene expression during Drosophila embryogenesis. Genome Biol 2002, 3(12):RESEARCH0088.

44. Gonzalez J, Casals F, Ruiz A: Duplicative and conservative transpositions of larval serum protein I genes in the genus Drosophila. Genetics 2004, I 68(I):253-264.

45. Crosby MA, Goodman IL, Strelets VB, Zhang P, Gelbart WM: FlyBase: genomes by the dozen. Nucleic Acids Res 2007:D486-49I.

46. Russo CA, Takezaki N, Nei M: Molecular phylogeny and divergence times of drosophilid species. Mol Biol Evol 1995 I 2(3):39|-404.

47. Vincent JP, Girdham $\mathrm{CH}, \mathrm{O}$ 'Farrell $\mathrm{PH}$ : A cell-autonomous, ubiquitous marker for the analysis of Drosophila genetic mosaics. Dev Biol 1994, I64(I):328-331.

48. Oberstein A, Pare A, Kaplan L, Small S: Site-specific transgenesis by Cre-mediated recombination in Drosophila . Nat Methods 2005, 2(8):583-585.

49. Groth AC, Fish M, Nusse R, Calos MP: Construction of transgenic Drosophila by using the site-specific integrase from phage phiC3I. Genetics 2004, I66(4): I775-I782.

50. Sambrook J, Fritsch EF, Maniatis T: Molecular cloning: A laboratory manual. 2nd edition. New York: Cold Spring Harbor Laboratory Press; 1989.

5I. Maroni G, Stamey SC: Use of blue food to select synchronous, late third instar larvae. Drosophila Information Service 1983, 59:142-143.

52. Spradling AC, Rubin GM: Transposition of cloned P-Elements into Drosophila germ line chromosomes. Science 1982, 21 8:34|-347.

53. Deryckere F, Gannon F: A one-hour minipreparation technique for extraction of DNA-binding proteins from animal tissues. Biotechniques 1994, 16:405.

54. Miura K, Wang S, Raikhel AS: Two distinct subpopulations of ecdysone receptor complex in the female mosquito during vitellogenesis. Molecular and Cellular Endocrinology 1999, I56(I2): III-I 20.

55. Sachs LM, Shi Y: Targeted chromatin binding and histone acetylation in vivo by thyroid hormone receptor during amphibian development. PNAS 2000, 97(24):|3|38-|3|43.

56. Thompson JD, Gibson TJ, Plewniak F, Jeanmougin F, Higgins DG: The CLUSTAL $X$ windows interface: flexible strategies for mul- tiple sequence alignment aided by quality analysis tools. Nucleic Acids Res 1997, 25(24):4876-4882

57. Swofford DL: PAUP*. Phylogenetic analysis using parsimony (*and other methods), version 4.I0b. Sinauer Associates, Sunderland Publishing; 2002.

58. Abascal F, Zardoya R, Posada D: ProtTest: selection of best-fit models of protein evolution. Bioinformatics 2005, 2I(9):2104-2105.

59. Whelan S, Goldman N: A general empirical model of protein evolution derived from multiple protein families using a maximum-likelihood approach. Mol Biol Evol 200I, I 8(5):69I-699.

60. Guindon S, Gascuel O: A simple, fast, and accurate algorithm to estimate large phylogenies by maximum likelihood. Syst Biol 2003, 52(5):696-704.

61. Naumann U, Scheller K: Complete cDNA and gene sequence of the developmentally regulated arylphorin of Calliphora vicina and its homology to insect hemolymph proteins and arthropod hemocyanins. Biochem Biophys Res Commun I991, I77(3):963-972.

62. D. melanogaster annotated genome (gadfly rel. 4.3), ChIP on chip profiles - nimblegen tiling arrays [http:// wpl054.bio.med.uni-muenchen.de/cgi-perl/gbrowse/genomel/]
Publish with Biomed Central and every scientist can read your work free of charge

"BioMed Central will be the most significant development for disseminating the results of biomedical research in our lifetime. "

Sir Paul Nurse, Cancer Research UK

Your research papers will be:

- available free of charge to the entire biomedical community

- peer reviewed and published immediately upon acceptance

- cited in PubMed and archived on PubMed Central

- yours - you keep the copyright
BiolMedcentral 